\title{
Multipurpose Sand Screening Machine
}

\author{
Mr. Pranit S. Patil ${ }^{1}$, Mr. Shubham. S. Jagadale ${ }^{1}$, Mr. Akshay G. Phadtare ${ }^{1}$, Mr. Swapnil S. Patil ${ }^{1}$, \\ Miss. Archana A. Pawar ${ }^{1}$, Mr. Rahul P. Suryawanshi ${ }^{2}$ \\ Students, Dept of Mechanical Engineering, Dr. Daulatrao Aher College of Engineering, Karad, Maharashtra ${ }^{1}$ \\ Asst. Professor, Dept of Mechanical Engineering, Dr. Daulatrao Aher College of Engineering, Karad, Maharashtra ${ }^{2}$
}

\begin{abstract}
This paper presents the concept of Multi-Function Operating Machine mainly carried out for production based industries. Industries are basically meant for Production of useful goods and services at low production cost, machinery cost and low inventory cost. Today in this world every task have been made quicker and fast due to technology advancement but this advancement also demands huge investments and expenditure, every industry desires to make high productivity rate maintaining the quality and standard of the product at low average cost. We have developed a conceptual model of a machine which would be capable of performing different operation simultaneously $\mathrm{y}$, and it should be economically efficient .In this machine we are actually giving drive to the main shaft to which scotch yoke mechanism is directly attached, scotch yoke mechanism is used for sawing operation. On the main shaft we have use bevel gear system for power transmission at two locations. Through bevel gear we will give drive to drilling centre and grinding centre. The model facilitate us to get the operation performed at different working centre simultaneously as it is getting drive from single power source. Objective of this model are conservation of electricity (power supply), reduction in cost associated with power usage, increase in productivity, reduced floor space.
\end{abstract}

Keyword: Sand screening, Wooden cutter, Grinder etc.

\section{INTRODUCTION}

Industries are basically meant for Production of useful goods and services at low production cost, machinery cost and low inventory cost. Today in this world every task have been made quicker and fast due to technology advancement but this advancement also demands huge investments and expenditure, every industry desires to make high productivity rate maintaining the quality and standard of the product at low average cost In an industry a considerable portion of investment is being made for machinery installation. So in this paper we have a proposed a machine which can perform operations like drilling, sawing, shaping, some lathe operations at different working centers simultaneously which implies that industrialist have not to pay for machine performing above tasks individually for operating operation simultaneously.

Economics of manufacturing: According to some economists, manufacturing is a wealth-producing sector of an economy, whereas a service sector tends to be wealthconsuming. Emerging technologies have provided some new growth in advanced manufacturing employment opportunities in the Manufacturing Belt in the United States. Manufacturing provides important material support for national infrastructure and for national defence

\section{LITERATURE REVIEW}

Before starting our work we have undergone through many research papers which indicates that for a production based industries machine installation is a tricky task as many factor being associated with it such as power consumption (electricity bill per machine), maintenance cost, no of units produced per machine i.e. capacity of machine, time consumption and many more....

Some research papers which have led us to approach to the idea of a machine which may give solution to all these factors are as follows:

Heinrich Arnold1 November 2001: Rather long reinvestment cycles of about 15 years have created the notion that innovation in the machine tool industry happens incrementally. But looking at its recent history, the integration of digital controls technology and computers into machine tools have hit the industry in three waves of technology shocks. Most companies underestimated the impact of this new technology. This article gives an overview of the history of the machine tool industry since numerical controls were invented and introduced and analyzes the disruptive character of this new technology on the market. About 100 interviews were conducted with decision-makers and industry experts who witnessed the development of the industry over the last forty years. The study establishes a connection between radical technological change, industry structure, and competitive environment. It reveals a number of important occurrences and interrelations that have so far gone unnoticed.

Dr. Toshimichi Moriwaki (2006): Recent trends in the machine tool technologies are surveyed from the view points of high speed and high performance machine tools, combined multifunctional machine tools, ultra precision 
IARJSET

machine tools and advanced and intelligent control non-rotating toothed part, called a rack, thereby producing technologies.

translation instead of rotation.

Frankfurt-am Main, 10 January 2011. : The crisis is 3.2 Methodology

over, but selling machinery remains a tough business. The proposed work will be carried out with following Machine tools nowadays have to be veritable "jack of all steps.

trades", able to handle all kinds of materials, to manage without any process materials as far as possible, and be capable of adapting to new job profiles with maximized flexibility. Two highly respected experts on machining and forming from Dortmund and Chemnitz report on what's in store for machine tool manufacturers and users.

\section{PROPOSED METHODOLOGY}

In this project we will generally give the power supply to the shaft on which a bevel gear is mounted on it, and a second bevel gear at a right angle to it has been mounted on a drill shaft to which a drill bit is being attached. At one end of the shaft is connected to power supply, other end is being joined to a circular disc ,through this circular disc scotch yoke mechanism is being performed (rotator $\mathrm{y}$ motion is converted to reciprocating motion). Also in between these two , a helical gear is mounted

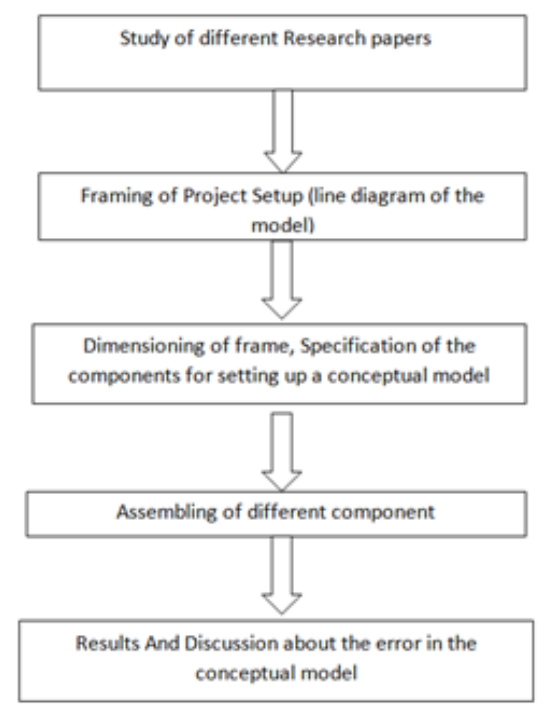

Fig. Flow Chart

\subsection{Experimental Set-Up}

In this conceptual model we have involved the gear arrangement for power transmission at different working centers, basically gear or cogwheel is a rotating machine part having cut teeth, or cogs, which mesh with another toothed part in order to transmit torque, in most cases with teeth on the one gear being of identical shape, and often also with that shape on the other gear. Two or more gears working in tandem are called a transmission and can produce a mechanical advantage through a gear ratio and thus may be considered a simple machine. Geared devices can change the speed, torque, and direction of a power source. The most common situation is for a gear to mesh with another gear; however, a gear can also mesh with a
1. Study of different operation which is need for fabrication shop and home appliences

2. Development of flow chart for design project.

4. Study of various types of multi operational machine

5. Calculation of Geometrical Parameters

6. Actual Manufacturing of project

7. Component Selection for the project

8. Experimentation by assembling all components

9. Testing

\subsection{Reciprocating motion}

It is also called reciprocation, is a repetitive up-and-down or back-and-forth linear motion. It is found in a wide range of mechanisms, including engines and pumps. The two opposite motions that comprise a single reciprocation cycle are called strokes A crank can be used to convert circular motion into reciprocating motion, or conversely turn reciprocating motion into circular motion. Reciprocating motion is clearly visible in early steam engines, particularly horizontal stationary engines and outside-cylindered steam locomotives, as the crank and connecting-rod usually are not enclosed.

Reciprocating motion is close to, but different from, sinusoidal simple harmonic motion. The point on the camshaft which connects the connecting rod rotates smoothly at a constant velocity in a circle. Thus, the horizontal displacement, of that point, is indeed exactly sinusoidal by definition. However, during the cycle, the angle of the connecting rod changes continuously. So, the horizontal displacement of the "far" end of the connecting rod (i.e., connected to the piston) differs from sinusoidal.

\subsection{Mechanism}

Mechanisms may be deboned as the division of machine design concerned with the kinematic Design of linkages, cams, gears, and gear trains. Kinematic design is the design on the basis of Motion requirements in contrast to the design on basis of strength requirements. The study of Mechanisms and machines is an applied science used to understand the relation between the Motions of their elements and the forces producing these motions within some geometrical Constraints. With the continuous advances in designing instruments and automated systems, The study of mechanisms becomes of great importance. This chapter is concerned with the Study of simple mechanisms topological structure, kinematic diagram, inversions, mobility Index, degrees of freedom, geometric constraints, and geometry of motion. The functions of Many important mechanisms are also included. These items are important for the study of Mechanism motion. The chapter is organized in over main sections: 
IARJSET

(a) Basic definitions and mechanism elements

(b) Kinematic chain, kinematic diagram and mechanism inversions

(c) Examples of important mechanisms

(d) Mobility index, degrees of freedom, geometric constraints, redundancy, and audibility

(e) Mechanism topology and geometry of motion The chapter also includes 4 solved examples and ends by a set of problems.

\section{GEARS FOR CONNECTING INTERSECTING SHAFTS}

\subsection{Straight Bevel Gear}

Bevel gears are useful when the direction of a shaft's rotation needs to be changed. They are usually mounted on shafts that are 90 degrees apart, but can be designed to work at other angles as well. The teeth on bevel gears can be straight, spiral or hypoid. Straight bevel gear teeth actually have the same problem as straight spur gear teeth as each tooth engages, it impacts the corresponding tooth all at once.

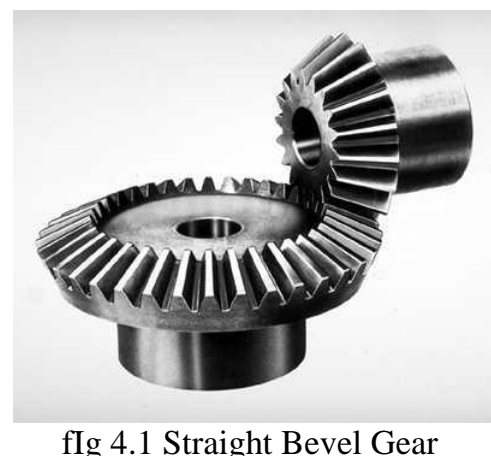

\subsection{BEVEL GEAR}

Just like with spur gears, the solution to this problem is to curve the gear teeth. These spiral teeth engage just like helical teeth: the contact starts at one end of the gear and progressively spreads across the whole tooth.

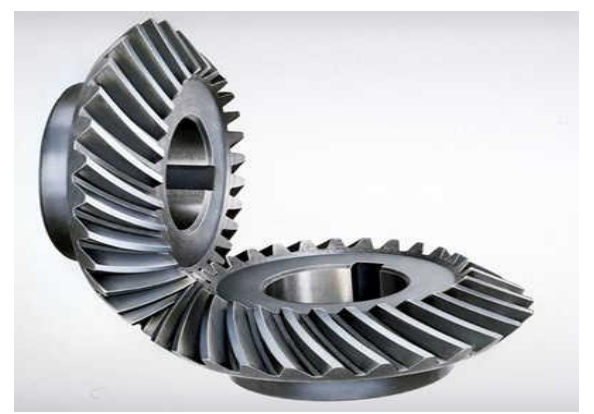

fig 4.2Straight Bevel Gear

\subsection{SPIRAL BEVEL GEAR}

On straight and spiral bevel gears, the shafts must be perpendicular to each other, but they must also be in the same plane. If you were to extend the two shafts past the gears, they would intersect the bevel gear has many diverse applications such as locomotives, marine applications, automobiles, printing presses, cooling towers, power plants, steel plants, railway track inspection machines, etc.

\section{MACHINE EQUIPMENTS}

The following components are the major components of the multi process machine.

\subsection{Drilling}

A drill is a tool fitted with a cutting tool attachment, usually a drill bit used for drilling holes in various materials or fastening various materials together with the use of fasteners. The attachment is gripped by a chuck at one end of the drill and rotated while pressed against the target material. The tip of the cutting tool does the work of cutting into the target material. Drills are commonly used in woodworking, metalworking and construction.

\subsection{Shaping}

Shaper operates by moving a hardened cutting tool backwards and forwards across the workpiece. On the return stroke of the ram the tool is lifted clear of the work piece, reducing the cutting action to one direction only. The work piece mounts on a rigid, box shaped table in front of the machine. The height of the table can be adjusted to suit this work piece, and the table can transverse sideways underneath the reciprocating tool which is mounted on the ram, the table motion is usually under the control of an automatic feed mechanism which acts on the feed screw.

\subsection{Cam arrangement}

A cam is a rotating or sliding piece in a mechanical linkage used especially in transforming rotary motion into linear motion or vice-versa. It is often a part of a rotating wheel (e.g. an eccentric wheel) or shaft (e.g. a cylinder with an irregular shape) that strikes a lever at one or more points on its circular path. The cam can be a simple tooth, as is used to deliver pulses of power to a steam hammer, for example, or an eccentric disc or other shape that produces asmooth reciprocating (back and forth) motion in the follower, which is a lever making contact with the cam.

\subsection{Bevel gear}

A bevel gear is a type of mechanical gear. These gears where the axes of the two shafts intersect and the tooth bearing faces of the gears themselves are conically shaped. Bevel gears are most often mounted on shafts that are 90 degrees apart, but can be designed to work at other angles as well. The pitch surface of bevel gears is a cone.

\subsection{Hydraulic bottle jack}

Bottle jacks are hydraulic jacks that are placed in a horizontal position. These jacks push against a lever, which lifts the main lift arm. Bottle jacks have a longer 
IARJSET

handle than most hydraulic jacks, however, and it is possible to get more lift per stroke with the increased leverage they provide when compared to regular models of jacks. Bottle jacks are versatile because their horizontal position makes it possible to place them in tight spots and provides good leverage. Recently bottle jacks have proven useful in search and rescue missions following earthquake damage.

\subsection{Vice}

It is a device consisting of two parallel jaws for holding a work piece; one of the jaws is fixed and the other movable by a screw, a lever, or a cam. When used for holding a work piece during hand operations, such as filing, hammering, or sawing, the vise may be permanently bolted to a bench. In vises designed to hold metallic work pieces, the active faces of the jaws are hardened steel plates, often removable, with serrations that grip the work piece; to prevent damage to soft parts, the permanent jaws can be covered with temporary jaws made from sheet copper or leather. Pipe vises have double V-shaped jaws that grip in four places instead of only two.

\subsection{Bearing}

A bearing is a device to permit constrained relative motion between two parts, typically rotation or linear movement. Bearings may be classified broadly according to the motions they allow and according to their principle of operation. Low friction bearings are often important for efficiency, to reduce wear and to facilitate high speeds. Essentially, a bearing can reduce friction by virtue of its shape, by its material, or by introducing and containing a fluid between surfaces. By shape, gains advantage usually by using spheres or rollers.

\section{APPLICATION}

-Generation of electric power

-Separating

-Drilling

- Cutting

-Grinding

\section{CONCLUSION}

We can see that all the production based industries wanted low production cost and high work rate which is possible through the utilization of multi-function operating machine which will less power as well as less time, since this machine provides working at different center it really reduced the time consumption up to appreciable limit.

In an industry a considerable portion of investment is being made for machinery installation. So in this paper we have proposed a machine which can perform operations like drilling, sawing, grinding at different working centers simultaneously which implies that industrialist have not to pay for machine performing above tasks individually for operating operation simultaneously.

\section{REFERENCES}

[1]. Heinrich Arnold1"The recent history of the machine tool industry and the effects of technological change "University of Munich, Institute for Innovation Research and Technology Management, November 2001.

[2]. Dr. Toshimichi Moriwaki "Trends in Recent Machine Tool Technologies" Professor Department f Mechanical Engineering Kobe University ,NTN Technical Review No.74(2006).

[3] T. Moriwaki "Multi-functional machine tool", Department of Industrial and Systems Engineering, Setsunan University, Neyagawa, Japan CIRP Annals - Manufacturing Technology DOI:10.1016/j.cirp.2008.09.004 .

[4]. Frankfurt am Main "Multi-purpose machines ensure enhanced ", 1 January 11 .

[5]. "Selecting and Planning the Process of Manufacture: Dr. Pulak M.Pandey. http://paniit.iitd.ac.in/ pmpandey

[6]. Wikipedia.

[7]. Fadooengineers.com.

[8]. www.Scribd.com. 